\title{
Anesthetic considerations during heart-lung transplantation in a patient with an unresectable pulmonary artery sarcoma
}

\author{
Heon-Yong Bae, Hyo Jung Son, Kyung-Don Hahm, Ji-Yeon Sim, and In-Cheol Choi \\ Department of Anesthesiology and Pain Medicine, Asan Medical Center, University of Ulsan College of Medicine, Seoul, Korea
}

Since the first report of a primary pulmonary artery sarcoma in 1923 [1], several hundred patients have been described. The diagnosis of such sarcomas is often delayed or established after death because the symptoms are nonspecific and survival time is limited. Mean survival time without surgical resection is 1.5 months, but may be as long as 10 months after surgical resection [2]. Early diagnosis and radical resection, including pneumonectomy, local excision, and endarterectomy, are necessary for more favorable survival outcomes. Heart-lung transplantation (HLT) is considered an alternative for patients who cannot undergo complete surgical resection. We describe here the outcomes of HLT in a patient with an unresectable pulmonary artery sarcoma.

A 49-year-old female patient was admitted with progressive dyspnea and cough of 10 months' duration. She was diagnosed with a pulmonary artery sarcoma, which could not be resected completely. We therefore elected to perform HLT. Prior to induction, a 5-lead electrograph, non-invasive hemodynamometer, pulse oximeter, BIS sensor, and cerebral oxymetry sensor were placed and monitored. Anesthesia was induced with bolus doses of etomidate and rocuronium and a continuous infusion of $2 \%$ propofol and remifentanil. Endotracheal intubation with a 37 French double lumen tube was performed uneventfully. A central venous catheter with a Swan-Ganz catheter was placed in the left internal jugular vein and another central venous catheter was placed in the right subclavian vein. During the procedure, anesthesia was maintained with oxygen and a continuous infusion of remifentanil, propofol and rocuronium.

HLT was performed through a median sternotomy. To reduce cardiopulmonary bypass (CPB) time, we attempted to dissect the lung using one-lung ventilation. During the CPB period, a double lumen tube was changed to a single lumen tube of internal diameter $7.0 \mathrm{~mm}$. CPB was started in the usual manner with bicaval cannulation and aortic cross-clamping, followed by cardiectomy. The bronchi were clamped, and both lungs were removed separately. Only the posterior pericardium, the right atrial cuff with the vena cavae, and the cut ends of the distal trachea and the proximal ascending aorta were left in the thorax. After the donor heart-lung bloc was placed in the recipient's chest, tracheal anastomoses were performed. The endotracheal tube was placed exactly at the anastomosis site by checking the position of the tip of the tube using a fiberoptic bronchoscope, followed by anastomosis of the right atrium and aorta.

Following completion of the aortic anastomosis, ventilation with low tidal volume $(4-5 \mathrm{ml} / \mathrm{kg})$ was started. The patient was given prostaglandin $\mathrm{E}_{1}\left(\mathrm{PGE}_{1}\right) 0.05 \mu \mathrm{g} / \mathrm{kg} / \mathrm{min}$, inhaled prostacyclin $\mathrm{I}_{2}\left(\mathrm{PGI}_{2}\right) 60 \mu \mathrm{g}$ and $20 \mathrm{ppm}$ of inhaled $\mathrm{NO}$ to prevent pulmonary hypertension. Isoproterenol $0.05 \mu \mathrm{g} / \mathrm{kg} /$ min and dopamine $5 \mu \mathrm{g} / / \mathrm{kg} / \mathrm{min}$ were started and the infusion rate was titrated to yield a heart rate of 90 to 100 beats/min. CPB was discontinued without difficulty, and vital signs after weaning were stable (Table 1 ), with a mean arterial pressure of $65 \mathrm{mmHg}$, a mean pulmonary arterial pressure of $16 \mathrm{mmHg}$, a heart rate of 118 beats $/ \mathrm{min}$, and a central venous pressure of 12 $\mathrm{mmHg}$. The total ischemic time was 136 minutes and the CPB time was 192 minutes. During surgery, the patient received 2 units of packed red blood cells, 3 units of fresh frozen plasma,

Corresponding author: In-Cheol Choi, M.D., Ph.D., Department of Anesthesiology and Pain Medicine, Asan Medical Center, University of Ulsan College of Medicine, 388-1, Pungnap 2-dong, Songpa-gu, Seoul 138-736, Korea. Tel: 82-2-3010-3862, Fax: 82-2-3010-6790, E-mail: icchoi@amc.seoul.kr (c) This is an open-access article distributed under the terms of the Creative Commons Attribution Non-Commercial License (http:// creativecommons.org/licenses/by-nc/3.0/), which permits unrestricted non-commercial use, distribution, and reproduction in any medium, provided the original work is properly cited. 
Table 1. Perioperative Hemodynamic Variables and Doses of Drugs Infused into Our Patient

\begin{tabular}{|c|c|c|c|c|c|c|c|}
\hline & $P$ & Wo & W2 & POD 1 (ICU) & POD 2 (ICU) & POD 5 (ICU) & POD 7 (WARD) \\
\hline RAP (S/D/M; mmHg) & $110 / 60 / 76$ & $105 / 55 / 72$ & $100 / 50 / 66$ & $134 / 66 / 89$ & $123 / 65 / 84$ & $150 / 75 / 100$ & $130 / 73 / 92$ \\
\hline HR (bpm) & 80 & 110 & 100 & 89 & 108 & 99 & 102 \\
\hline CVP (mmHg) & 7 & 12 & 14 & 10 & 15 & 7 & - \\
\hline PAP (S/D/M; mmHg) & $42 / 19 / 27$ & $25 / 15 / 19$ & $23 / 16 / 18$ & $20 / 15 / 11$ & $21 / 14 / 16$ & - & - \\
\hline \multicolumn{8}{|l|}{ Inotropics $(\mu \mathrm{g} / \mathrm{kg} / \mathrm{min})$} \\
\hline Dopamine & 5 & 10 & 5 & - & - & - & - \\
\hline Dobutamine & - & - & - & 8 & 4 & - & - \\
\hline Isoproterenol & - & 0.05 & 0.05 & - & - & - & - \\
\hline Norepinephrine & - & - & - & 0.05 & 0.05 & - & - \\
\hline \multicolumn{8}{|l|}{ Other drugs $(\mu \mathrm{g} / \mathrm{kg} / \mathrm{min})$} \\
\hline PGE1 & - & 0.05 & 0.05 & 0.05 & 0.025 & 0.025 & - \\
\hline Isoket & - & 0.5 & 0.5 & 0.5 & 0.5 & 1 & - \\
\hline
\end{tabular}

P: Pre-CPB period, W0: immediately after weaning from CPB, W2: 2 hours after weaning from CPB, POD: postoperative day, RAP: radial artery pressure, S: systolic, D: diastolic, M: mean, HR: heart rate, CVP: central venous pressure, PAP: pulmonary artery pressure.

10 units of platelets, $2,000 \mathrm{ml}$ of crystalloid solution and $1000 \mathrm{ml}$ of colloid solution.

The first successful HLT occurred in 1981, with long-term survival requiring cyclosporine [3]. HLT has since been considered a therapeutic option for patients with end-stage cardiopulmonary and lung diseases. Among the disadvantages of HLT is the need to procure a heart-lung bloc, resulting in long wait times and increased mortality awaiting a donor. In addition, HLT requires CPB during surgery, and these patients receive denervated hearts. Thus, single or double lung transplantation is preferred to HLT in patients with parenchymal lung disease. However, HLT also has several advantages over single or double lung transplantation, including better tracheal healing. Following HLT, the donor trachea and lungs are supplied by blood from the right bronchial artery, whereas, following lung transplantation alone, there is no bronchial blood supply. Second, HLT minimizes ventilation and perfusion defects by removal of all diseased tissue.

The primary anesthetic goals during HLT are to avoid hypercapnia and hypoxemia, which increase pulmonary hypertension and may result in right ventricular failure. In addition, it is necessary to maintain or increase pre-existing left or right ventricular function, and to avoid sudden decreases in systemic vascular resistance or increases in pulmonary vascular resistance, especially in patients with Eisenmenger's syndrome. These sudden changes may increase right-to-left shunting and exacerbate hypoxemia. Slow and smooth induction are essential because of high pulmonary vascular resistance and low cardiac output. Since the need for CPB is not always predictable, it is necessary to prepare for the use of $\mathrm{CPB}$ at any time during the procedure. $\mathrm{CPB}$ is indicated in patients unable to maintain oxygenation or arterial pressure. After anastomosis of the trachea, the lungs are gently inflated to check for leakage.
Rapid re-inflation of the lung can cause pulmonary injury or edema. After anastomosis of the heart, termination of CPB is indicated. Ventilation with low tidal volume $(4-5 \mathrm{ml} / \mathrm{kg})$ and 5-10 $\mathrm{cmH}_{2} \mathrm{O}$ PEEP is helpful. Isoproterenol, a potent inotrope and vasodilator, together with dopamine, epinephrine and/or dobutamine are usually used to enhance or maintain cardiac output during the post-CPB period. The ability to manipulate right ventricular afterload and pulmonary vascular resistance is important because poor preservation of the heart and lungs can impair right heart function. Pulmonary vasodilators, such as $\mathrm{PGE}_{1}, \mathrm{PGI}_{2}$, inhaled $\mathrm{NO}$ and nitroglycerin, are useful in preventing pulmonary hypertension and to reduce right ventricular afterload.

In conclusion, despite the small number of HLTs that are performed, it is still a main therapeutic option for some patients, such as those with congenital heart disease and Eisenmenger's syndrome, idiopathic pulmonary arterial hypertension and cystic fibrosis. Appropriate intra-operative management requires anesthesiologists to know the special patient requirements during this type of surgery.

\section{References}

1. Mandelstamm M. Uber primare Neublildungen des Herzen. Virchows Arch A 1923; 245: 43-54.

2. Krüger I, Borowski A, Horst M, De Vivie E, Theissen P, GrossFengels W. Symptoms, diagnosis, and therapy of primary sarcomas of the pulmonary artery symptome, diagnose und therapie eines primären Sarkoms der Arteria pulmonalis. Thorac Cardiovasc Surg 1990; 38: 91-5.

3. Reitz BA, Wallwork JL, Hunt SA, Pennock JL, Billingham M, Oyer PE, et al. Heart-lung transplantation: successful therapy for patients with pulmonary vascular disease. N Engl J Med 1982; 306: 557-64. 